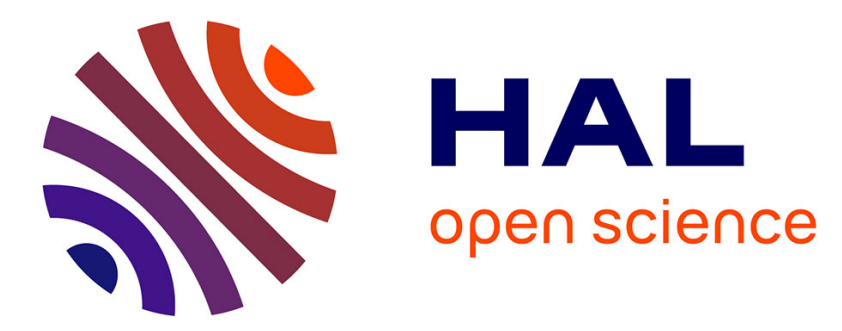

\title{
Transfer dynamics of macroplastics in estuaries - New insights from the Seine estuary: Part 3. What fate for macroplastics?
}

\author{
R. Tramoy, Johnny Gasperi, L. Colasse, C. Noûs, B. Tassin
}

\section{To cite this version:}

R. Tramoy, Johnny Gasperi, L. Colasse, C. Noûs, B. Tassin. Transfer dynamics of macroplastics in estuaries - New insights from the Seine estuary: Part 3. What fate for macroplastics? Marine Pollution Bulletin, 2021, 169, pp.112513. 10.1016/j.marpolbul.2021.112513 . hal-03236190

\section{HAL Id: hal-03236190 \\ https://hal-enpc.archives-ouvertes.fr/hal-03236190}

Submitted on 21 Jan 2022

HAL is a multi-disciplinary open access archive for the deposit and dissemination of scientific research documents, whether they are published or not. The documents may come from teaching and research institutions in France or abroad, or from public or private research centers.
L'archive ouverte pluridisciplinaire HAL, est destinée au dépôt et à la diffusion de documents scientifiques de niveau recherche, publiés ou non, émanant des établissements d'enseignement et de recherche français ou étrangers, des laboratoires publics ou privés. 


\title{
Transfer dynamics of macroplastics in estuaries - New insights from the Seine estuary: Part 3. What fate for macroplastics?
}

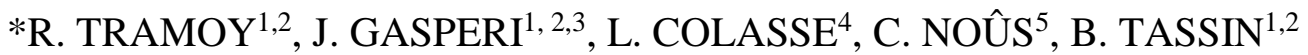

\author{
${ }^{1}$ Univ Paris Est Creteil, LEESU, F-94010 Creteil, France. \\ ${ }^{2}$ Ecole des Ponts, LEESU, F-77455 Champs-sur-Marne, France. \\ ${ }^{3}$ GERS-LEE, Université Gustave Eiffel, IFSTTAR, F-44344 Bouguenais, France. \\ ${ }^{4}$ Association SOS Mal de Seine, http://maldeseine.free.fr/ \\ ${ }_{5}^{5}$ Univ Paris Est Creteil, Laboratoire Cogitamus, F-94010 Creteil Cedex, France.
}

*Corresponding authors

Mail: romain.tramoy@enpc.fr; johnny.gasperi@univ-eiffel.fr

Tel: +33676280838

\begin{abstract}
Macroplastic emissions from the Seine estuary to the English Channel were estimated using institutional cleaning of riverbanks, combined with a tagged litter experiment. Cleaning were performed between March 2018 and April 2019 by the non-profit company Naturaul'un over 19 sites covering $20 \mathrm{~km}$ of riverbanks. A total of 365 tagged litter (90\% macroplastics) was released in the estuary in March $(n=200)$, at the end of the winter/spring flood 2018, in July ( $\mathrm{n}=58)$, August $(\mathrm{n}=56)$ and September $2018(\mathrm{n}=51)$ during low river flow periods. Over the total tagged litter, 102 (28\%) were recovered by Naturaul'un. Relative to the total amount of macroplastics $(>5 \mathrm{~cm}$ ) collected and the estimated amount of smaller/hidden macroplastics (>5 mm) not collected, the maximum macroplastic emission to the English Channel was estimated to be $\sim 100-200$ metric tons per year.
\end{abstract}

\section{Keywords}

Tagged litter, macroplastic emissions, institutional cleaning, flood, riverbanks

\section{Introduction}

This paper is the last one of a trilogy dedicated to the transfer dynamics of macroplastic debris in rivers and estuaries with a focus on the Seine River (France). After highlighting the 
very long residence time (up to decades) of macroplastic debris in the estuary using date-prints items (Part 1; Tramoy et al., 2020a), and studying the dynamics of macroplastic debris in the estuary using GPS trackers (Part 2, Tramoy et al., 2020b), the present paper is focusing on the macroplastic emission from the Seine estuary to the English Channel. It will be done thanks to a comprehensive analysis of all the knowledge acquired on the transfer dynamics of macroplastic debris in the estuary.

The two first papers confirm what the Seine river managers (local authorities, Seine Normandie Water agency, environmental NGOs) empirically know through their careful observation of the river, of its estuary, of its riverbanks: (i) the residence time of macroplastic debris in the estuary may reach several decades, (ii) they all strand on riverbanks for more or less long time, before being remobilized when the water level increases. One major question arises: What fate for macroplastics at the river-sea interface?

This is a major question since Jambeck_et_al__(2015) gave the first estimate of global plastic waste inputs from land (50 km from coastlines) into the ocean, i.e. $\sim 8$ million metric tons (mt) in 2010, leading to increasing interest in the scientific community about the plastic emissions from lands. More recently, new modelling attempts focused on river emissions and provided lower estimates, between 0.4 and 4 million mt/yr (Lebreton et al., 2017; Schmidt et al., 2017). But, the calibration data of the models were based on microplastic sampling performed with $300 \mu \mathrm{m}$ manta-trawls usually used in marine biology surveys. Model results were thus biased toward the microplastic fraction with a low spatiotemporal resolution, whereas the macroplastic fraction was deduced using a poorly documented ratio between micro- and macroplastics.

Unfortunately, field-based estimates of macroplastic emission are scarce and there is no consensus on an appropriate methodology to measure it. Macroplastic emissions into the ocean can be considered as a fraction of Mismanaged Plastic Waste (MPW) reaching the hydrosystem because all the waste management systems and strategies at the catchment scale failed to catch them. The direct assessment of this leak is thus impossible by nature. If it was possible, then it would also be possible to implement strategies in order to recover the corresponding debris and finally to eliminate the transfer of those debris from land into the oceans. Therefore, indirect methods must be developed to measure the quantity of plastics leaking into the ocean.

A first set of methods consists in passive observations of macroplastic debris over short time intervals. In this way, visual counting from bridges is preferred to net sampling, although both are sometimes conducted together (González-Fernández and Hanke, 2017; van Emmerik et al., 2018; Castro-Jiménez et al., 2019; Emmerik et al., 2019; van Emmerik et al., 2019b; 
Geraeds et al., 2019; Schöneich-Argent et al., 2020; Vriend et al., 2020b). Because of the low numeric concentration of macroplastics in water relative to microplastics, net sampling alone is in most cases unreliable in European rivers for macroplastic monitoring: devices able to intercept a representative fraction of the annual flux of macroplastics are necessary (Lechner et al., 2014; van der Wal et al., 2015). In addition, observation methods are based on punctual assessments and cannot take into account the spatiotemporal variability of the macroplastic debris transport unless monitoring frequency is considerably increased, which demand much efforts (Castro-Jiménez et al., 2019; van Emmerik et al., 2019a; van Emmerik and Schwarz, 2020). In estuaries, as macroplastic debris move up and down to the river following the tidal cycles (van Emmerik et al., 2018, 2019b; Schöneich-Argent et al., 2020), visual counting may be not relevant to assess net emissions of macroplastic debris.

In contrast, other studies focused on macroplastic debris stranded on riverbanks related to (i) the accumulation and source of macroplastic debris in estuaries (Acha et al., 2003; Bruge et al., 2018; Mazarrasa et al., 2019; Tramoy et al., 2019; Yao et al., 2019; Schöneich-Argent et al., 2020), (ii) the transfer dynamics of macroplastic debris (Ivar do Sul et al., 2014), (iii) the seasonal variations in plastic quantity and quality (Cheung et al., 2016; Kurniawan and Imron, 2019a), or (iv) the influence of hydro-meteorological parameters in plastic distribution (Browne et al., 2010; Krelling and Turra, 2019; Kurniawan and Imron, 2019b). According to Schöneich show the highest diversity when compared to macroplastics sampled in the water column, ate the water surface or on the riverbed. Together with our findings which state that subfloating and floating macroplastic debris are prone to strand on riverbanks (Tramoy et al., 2020b), this suggests that riverbanks integrate a great fraction of the total plastic pollution. Thus, investigating riverbanks, especially in macro-tidal estuaries, is a relevant approach to provide a better assessment and characterization of the macroplastic debris, and also to implement efficient mitigation strategies (Bernardini et al., 2020).

In addition to these points this paper shows an original and robust method which estimates macroplastic emissions to the English Channel, combining data from macroplastic debris collected on the riverbanks in the Seine estuary and their transfer dynamics. Because it relies on daily cleaning, this method has a great spatiotemporal representativeness. In parallel, tagged litter were voluntary released in the estuary to determine the fraction recovered by the institutional cleaning. Based on this rate of recovery, the annual macroplastic emission to the English channel is calculated considering that $100 \%$ (sub)floating macroplastics strand on riverbanks for hours to decades (Tramoy et al., 2020a, 2020b). Finally, results are discussed 
and compared to previous model- and field-based approaches in the Seine River, but also in other rivers worldwide.

\section{Material and methods}

\subsection{Macroplastic debris in the Seine estuary}

The Seine estuary is located in North-Northwest part of France and stretches from the Poses' Dam to the English Channel, which is about $350 \mathrm{~km}$ of riverbanks considering both sides (Figure 1A). The Seine River catchment is about $76,000 \mathrm{~km}^{2}$. It is densely populated with 16.7 million inhabitants, including12 millions in Paris Megacity, which constitutes potentially a major source of mismanaged plastic waste (MPW). The Seine estuary is characterized by numerous meanders and semidiurnal tides with a tidal range up to $7 \mathrm{~m}$ at the river mouth. According to its morphology and high tidal range, the Seine estuary is a macrotidal (Meybeck et al., 1998)) and well-mixed estuary (Grasso et al., 2018). The average mean flow is about $500 \mathrm{~m}^{3} / \mathrm{s}$ nearby Poses' Dam (Vernon). Summer low water flow is about $200 \mathrm{~m}^{3} / \mathrm{s}$ and the 10-year return period flow - with the last occurrence recorded during the winter/spring 2018 - reaches 2,000 m³/s (Vernon; http://www.hydro.eaufrance.fr). In the estuary, only water heights are measured at different stations like in Caudebec.

The transfer dynamics of macroplastic debris from the Seine catchment to the English Channel is controlled by several factors in the estuary over different spatial and time scales. Over large time and space scales (years to decades), the meandering character of the river which drives the connectivity of the floodplain river system - may increase the retention time of macroplastic debris to decades (Tramoy et al., 2020a). Over shorter time and space scales (days to months), tides and wind are the main drivers of the macroplastic transport under regular river discharge, leading to almost endless stranding/remobilization episodes (Tramoy et al., 2020b). Tides and wind may also control the stranding/remobilization processes. In contrast, flood events may counteract those dominant processes and help to flush macroplastic debris out of the estuary as suggested by significant higher up/downstream transport of macroplastic debris when compared to regular river discharge. Alternatively, flood events can lead to the deposition of a large amount of debris higher up on the riverbanks related to water level increase, leading to their long-term settlement until they are removed, buried or remobilized again at the next extreme event.

Accumulation zones of riverine litter are well known for more than 20 years (Lerond, 1997; SAFEGE, 2012). Since 2008 the non-profit company Naturaul'un oversees the cleaning of these zones. Accumulation sectors are cleaned up between 0.3 to 3.3 times per month (sup. 
data 1; Table S1) by a team of 4 to 6 people, working 6 hours per day and 5 days per week, and covering around $20 \mathrm{~km}$ linear. Downstream Naturaul'un' sectors, an NGO called 'La Maison de l'estuaire" also collects marine litter in the National Natural Reserve of the Seine estuary to prevent ecological damages related macroplastic debris. However, they perform cleaning less regularly than Naturaul'un. In the estuary, only natural or semi-natural riverbanks are cleaned, because anthropized riverbanks accumulate less riverine litter (except for stony embankment) and their access is not safe (GIP Seine-Aval, 2011).

\subsection{Methodology}

Since 2008, the quantity and composition of litter removed from the estuary is well known, but the fraction removed relative to the total riverine litter conveyed by the River remains unknown by nature. The aim of the tagged litter experiment was to determine this fraction following a capture/recapture experiment design. It consisted in release of tagged litter in the estuary to determine their recovery rate by Naturaul'un, which is in turn the collection rate of cleaning. Then, the annual macroplastic emission was calculated considering that $100 \%$ (sub)floating items can strand on riverbanks (Tramoy et al., 2020a, 2020b).

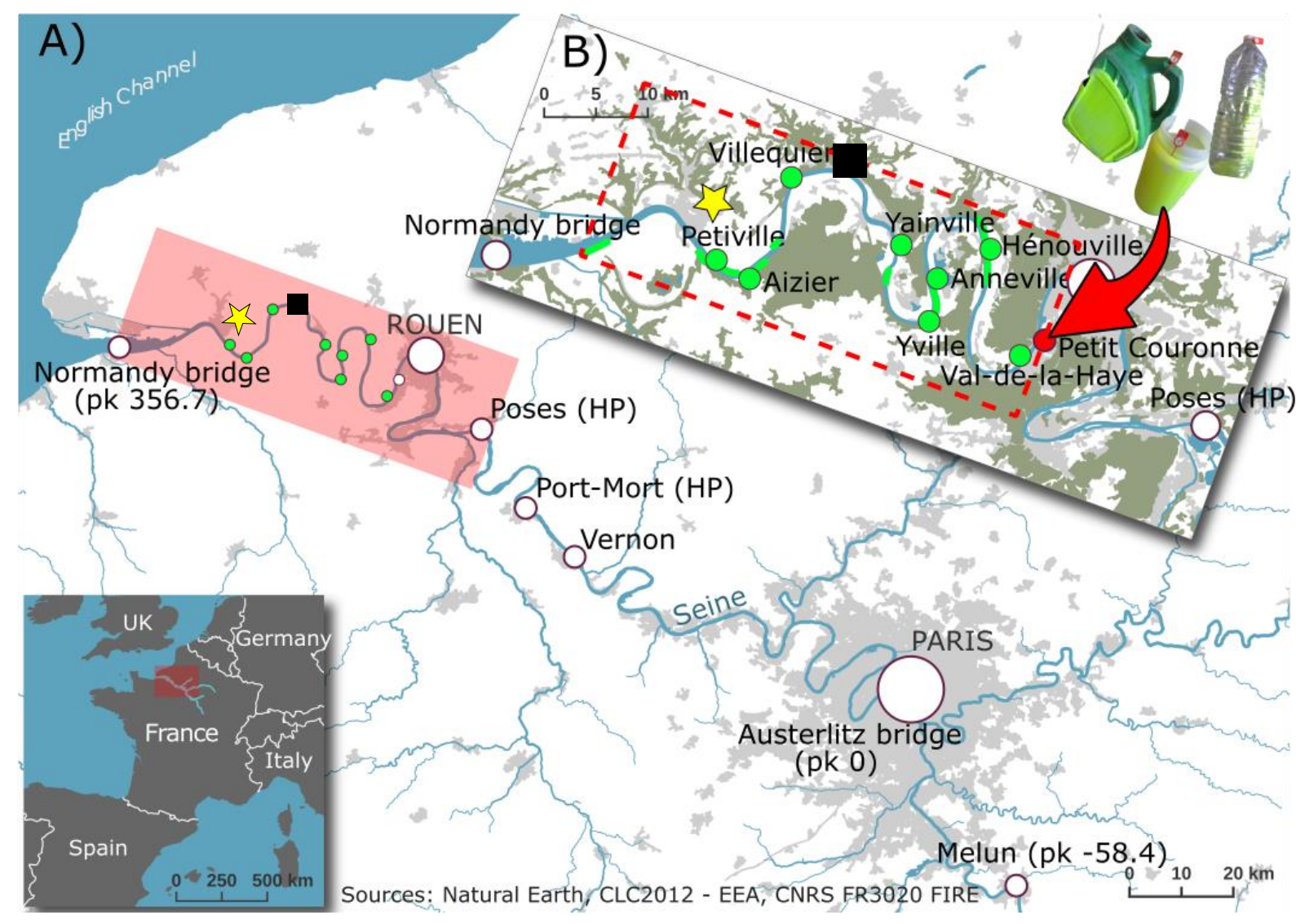


Figure 1: A, Geography of the Seine River with a focus on the estuary (reddish area). The black square corresponds to Caudebec station where water height is measured. The yellow star corresponds to Naturaul'un' location. B, The Seine estuary with the sites (green dots) and riverbanks (green lines) investigated by Naturaul'un. The dashed red square is the area in which the tagged litter were released from the start point in Petit Couronne (red dot; Lat. 49.385943; Long., 1.010085). This area was investigated during field campaigns once to twice a month and with citizen sciences for reporting of tagged litter.

\subsection{Plastic debris collection}

Naturaul'un collects in the estuary roughly $20 \mathrm{mt} / \mathrm{yr}$ of litter, in which $80 \%$ are plastics, i.e. $16 \mathrm{mt} / \mathrm{yr}$. Cleaned sites are chosen weekly among a list of 19 sites (supp. data 1; Table S1) regarding their proximity from the company location, their accessibility, their usual level of debris and their renewal rate of debris (empirical knowledge). For example, Villequier is one of the most investigated site, because it is the closest, the most accessible and the dirtiest. Whereas Val de La Haye is the less investigated site, because it is the farthest (Figure 1B). Note that the list of sites has changed since 2008. Several were abandoned in favor of others that were newly accessible for cleaning. As the main objective is to remove all visible litter as required by the authorities, there is no specific cleaning protocol to follow, but all visible and accessible litter should be removed at each site.

Workers preferentially collect litter during low tides for safety reasons and to get a better cleaning efficiency of the intertidal zone (Photo 1). They are on site from 9:00 am to 12:00 am, and between 1:00 pm and 4:00 pm. They manage to clean two sites per day if debris are not too numerous. A 4-6 worker team comes to the site with a trailer-truck. Workers are equipped with gloves, safety shoes and waste collection pliers. They pick up the biggest identifiable litter by hands and put them into the trailer. The rest is collected using waste collection pliers (Nifty Nabber) and put in a trash bag. At the end of the day, trash bags are weighed, and the biggest items are identified, listed and weighed by category material. Since 2008, four main categories are considered: plastics, wood, metals and others. But they were not weighed separately between 2008 and 2018 and plastic masses were estimated using a mass/volume ratio. However, debris characterization and quantification have greatly improved over time. Since 2018, the four categories are separately weighed, and hundreds of items are listed and counted, but in a way that do not enables any OSPAR classification; an international monitoring protocol of marine litter recently adapted to rivers, which aims to classify macrolitter relative to their material, usage and sources (van Emmerik et al., 2020). In addition, 
some of the items are used as indicators of the amount of litter removed over time like aerosol cans, glass bottles, syringes and plastic containers like planters in polypropylene, jugs or buckets (Figure 2).

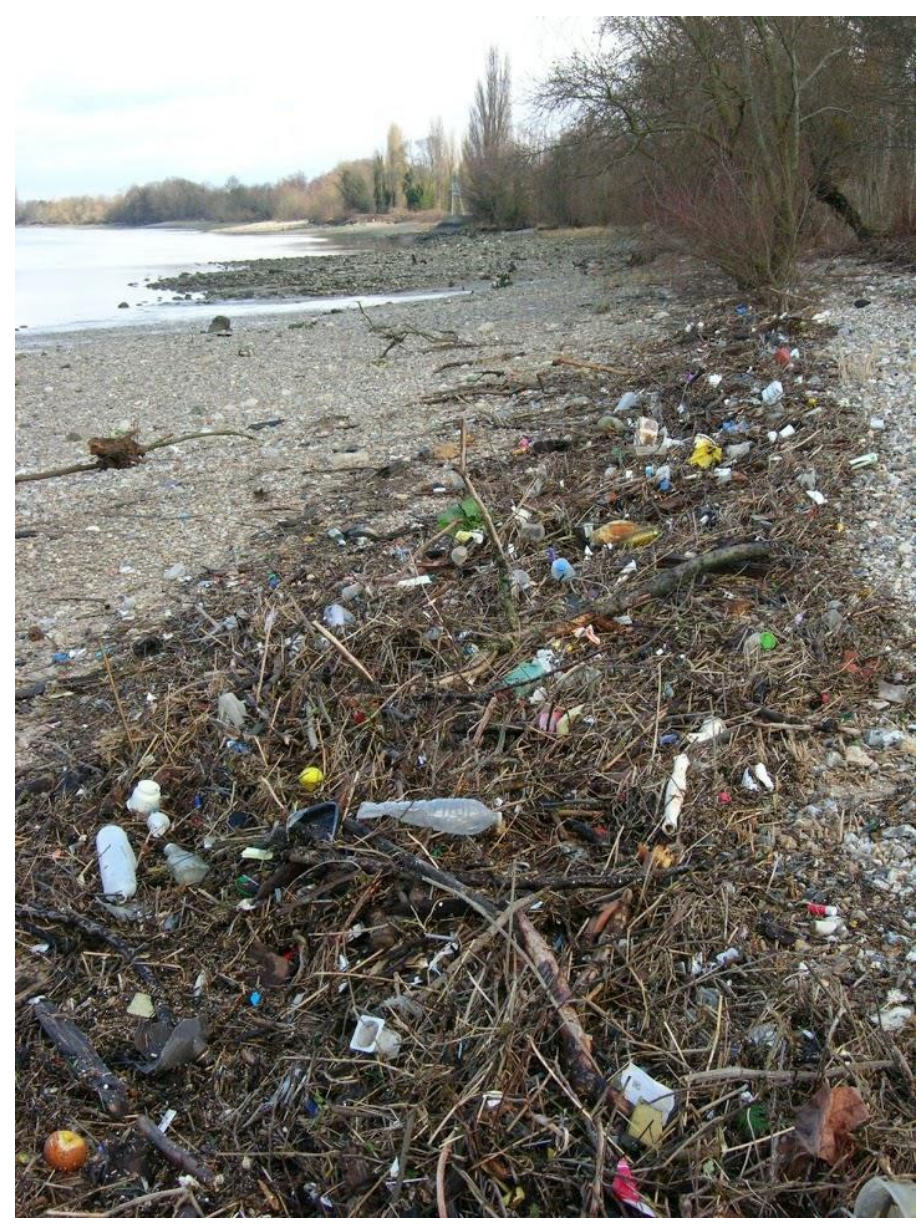

Photo 1: A tide line in the Seine estuary (August 2019) made of organic and plastic debris. Biggest items can be removed by Naturaul'un, but a significant fraction remains uncollected.

Despite few interruptions related to public procurement renewal, institutional cleaning of riverbanks show high spatiotemporal resolution with $\sim 20 \mathrm{~km}$ of riverbanks investigated at least every month over the $350 \mathrm{~km}$ of the estuary. When only natural and semi-natural riverbanks are considered ( $\sim 150 \mathrm{~km}$; GIP_Seine-_. riverbanks that are investigated in the estuary, either left (30\% of sites) or right ( $70 \%$ of sites). 


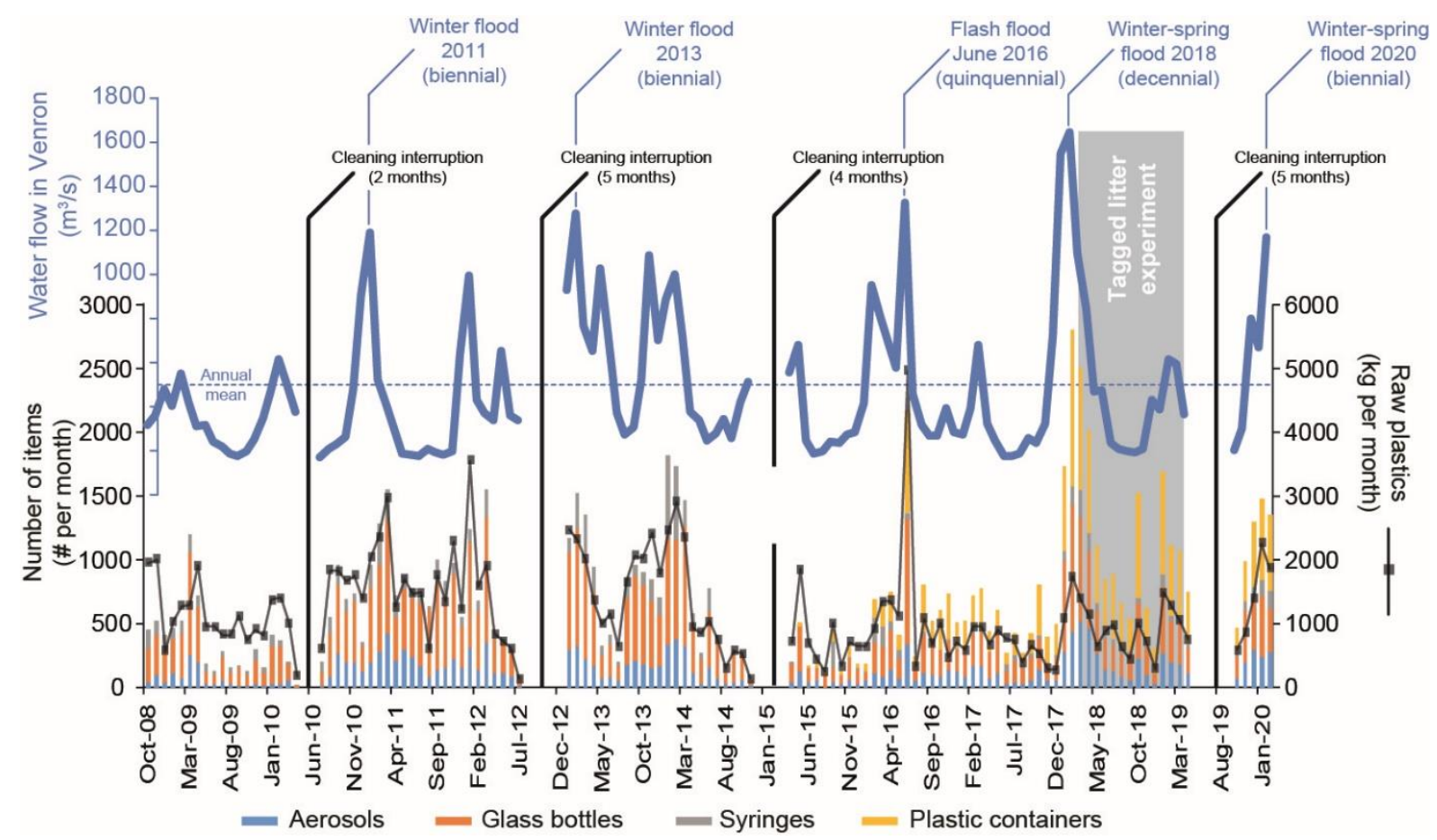

Figure 2: Amount of riverine litter collected by Naturaul'un in the Seine estuary since October 2008. The number and mass of the collected items roughly follows the water flow entering the estuary (blue curve, data from Vernon station). Notice cleaning are not continuous with several interruptions related to public procurement renewal. Our experiment extended between March 2018 and April 2019 (shaded area) until the last interruption. Plastic containers include planters, buckets and jugs which are separately counted since 2015 .

\subsection{Rate of litter collection based on capture/recapture design}

In order to determine the probability for a debris to be collected by Natural'un, and consequently, the opposite probability to remain in the estuary and potentially reach the English Channel, a capture/recapture experiment was designed using tagged litter. In total, 365 items previously collected by Naturaul'un were released in the estuary, at the beginning of the cleaning zone in Petit Couronne (Figure 1B). The list of the tagged litter and their characteristics is found in supp. data 1 (Table S2). Their mass distribution is found in supp. data 1 (Figure S3). The shape, size and mass of macroplastics released were very different with masses ranging from 8 to $749 \mathrm{~g}$ (median value of $39 \mathrm{~g}$ ) and with different polymers resulting in different buoyancies. Before release, items were marked with fluorescent yellow paint and tagged (number ID from 56001 to 56365) to be easily recognizable. They were all unique and pictured (supp. data 1; Photos S4). Because the study focused on macroplastic emissions, items consisted in 90\% macroplastics (PET-bottles, every sort of PE- and PPcontainers, lids, toys, large and unidentified fragments, tires, PVC-pipes, etc.), 5\% alumina 
(drinking cans and aerosol cans) and 5\% glass bottles. The $10 \%$ of other material was released to check if those materials were also able to be transported by the river, rather than resulting from illegal dumping.

All items were released during ebb tides from the ferry boat crossing the estuary in Petit-Couronne (Figure 1B). Items were equally distributed along the river cross-section, excluding the river edges to avoid instantaneous stranding. But they were not all released at the same time. First, 200 items were released March, $23^{\text {th }} 2018$ at the end of the decennial winterspring flood to simulate a huge input of litter into the estuary related to flood conditions. At this time, the river discharge reached $1120 \mathrm{~m}^{3} / \mathrm{s}$ in Vernon, which is more than two times the mean annual flow (http://www.hydro.eaufrance.fr). After the flood, 58 items were released July, $19^{\text {th }}\left(236 \mathrm{~m}^{3} / \mathrm{s}\right), 56$ August, $29^{\text {th }}\left(288 \mathrm{~m}^{3} / \mathrm{s}\right)$ and 51 September, $21^{\text {st }}\left(205 \mathrm{~m}^{3} / \mathrm{s}\right)$ to simulate lower but regular inputs under low water flow conditions.

To avoid tagged litter removal by other local authorities, NGOs or citizen, the experimental design was communicated to them through mailing and social networks. They were also invited to participate by reporting (by e-mail, phone number or facebook page "Projet MacroPLAST") any tagged litter found stranded on a riverbank, without taking it out. Items were counted as "recovered" only when Naturaul'un found them for the first time. Each item "recovered" was pictured, its ID number was recorded, the info sent to us, and the item was left in place. They were only removed when Naturaul'un found them at Villequier or downstream to prevent their potential transfer to the Sea. Otherwise, they were only reported and left in place. This enabled to identify stranding/remobilization episodes as revealed by GPS trajectories of macroplastic debris (Tramoy et al., 2020b). When only a fragment of tagged litter was found, it was identified using pictures and it was counted as one half or one third of the item released. That protocol was applied from March, $23^{\text {th }} 2018$ to April, $12^{\text {th }} 2019$, i.e. around one year facing different hydrological and meteorological conditions.

\subsection{Calculations of the macroplastic emissions}

Calculation of the upper limit of the macroplastic emission to the English Channel was based on the following hypotheses:

- H1: $100 \%$ of (sub)floating litter strand on riverbanks,

- H2: The fraction of tagged litter (including the $10 \%$ non-plastic items) recovered by Naturaul'un corresponds to the fraction of macroplastic debris they remove from the estuary, 
- H3: the mass of small and/or hidden macroplastic debris that are not collected by Natural'un can be assessed by a comprehensive collection of all macroplastic debris larger than $5 \mathrm{~mm}$, following additional collection after Naturaul'un,

- H4: The NGO "Maison de l'estuaire" collects every year a constant mass of macroplastic debris $\mathrm{M}_{\mathrm{mde}}$,

- H5: What is not collected may reach the Sea within a year.

H1 lies on the fact that all floating debris and even subfloating debris are submitted to stranding/remobilization episodes on riverbanks with a residence time into the estuary up to decades as suggested by date-prints on macroplastic debris and GPS-tracking of macroplastic debris (Tramoy et al., 2020a, 2020b).

$\mathrm{H} 2$ considers that the behavior of the tagged litter in the estuary is representative of the behavior of all macroplastic debris in the estuary.

$\mathrm{H} 3$ is related to field campaigns that showed huge amount of macroplastics are not removed by cleaning because (i) they are hidden and/or entangled in the organic debris which compose the tide lines, or (ii) they are too numerous/too small. To account for those uncollected macroplastics (> 5mm), we performed additional collection after Naturaul 'un' on two different collection sites: Yville and Anneville, (cf.Figure 1B). There, all macroplastic debris were collected, sorted and weighed. Both $\mathrm{a}_{\min }$ and $\mathrm{a}_{\max }$ were estimated, which are respectively the minimum and maximum value of the mass ratio between smaller/hidden macroplastics (uncollected by Naturaul'un) and larger/visible macroplastics (collected by Naturaul'un). In other words, this ratio corresponds to the mass of macroplastics collected by Naturaul'un relative to the mass of macroplastics left behind. The amin value was estimated by cleaning tide lines in Yville, on a gentle slope riverbank made of pebbles at its downstream part and muddy sediments with trees at its upstream part. Here, Naturaul'un collected macroplastics on $500 \mathrm{~m}^{2}$, whereas we collected the remaining macroplastic debris in 45 squares of $30 * 30 \mathrm{~cm}$ randomly distributed in this area. It gave a mass of macroplastics collected per square meter by Naturaul'un relative to a mass of macroplastics per square meter left behind, i.e. amin. Another protocol was applied in Anneville to get the $a_{\max }$ value, because litter was concentrated into a single tide line deposited on pebbles. Macroplastic debris were collected in this tide line by Naturaul'un along a linear of $20 \mathrm{~m}$ long. Then, we collected the remaining macroplastic debris on and into $50 \%$ of this linear. It gave a mass of macroplastics collected per meter by Naturaul'un relative to a mass of macroplastics per meter left behind, i.e. amax. See Supp. Data 
1 (Table S5, Photos S6, S7 and figures S8, S9) for additional explanations and details about $\mathrm{a}_{\min }$ and $\mathrm{a}_{\max }$ estimations.

$\mathrm{H} 4$ : Collecting debris is not the primary mission of the NGO "Maison de l'estuaire" but is one among others to maintain a good ecological status in the natural reserve, at the downstream part of the estuary (e.g. Biodiversity observatory, hydrological management, management of hunting activities, etc., http://maisondelestuaire.org/reserve_gestion.html). Debris are collected by volunteers once to several times a year in hardly accessible areas where they accumulate, before being removed. Data are gathered in technical reports and reported in volume without systematic characterization nor weighing (personal communication). Thus, the figure of $10 \mathrm{mt} / \mathrm{yr}$ collected is not as accurate as the data gathered by Naturaul'un and must be considered as an annual maximum.

H5 is a non-conservative hypothesis leading to upper estimates of macroplastic emissions within a year. It is non-conservative because tagged litter that have not been recovered on Naturaul'un' collection sites, may reach the sea one day, potentially after years, but also may remain stranded in other sites that are not investigated (Tramoy et al., 2020a, 2020b).

Following those hypotheses, and considering

$\mathrm{M}_{\text {naturaulun }}$, the yearly mass of macroplastic debris collected by Naturaul'un,

$\mathrm{M}_{\text {stranded }}$, the total annual mass of macroplastics stranded according to H1 and H3,

$\mathrm{M}_{\text {estuary }}$, the total annual mass of macroplastics in the estuary,

$\mathrm{M}_{\mathrm{mde}}$, the total annual mass of macroplastics collected by the NGO "Maison de l'estuaire" according to $\mathrm{H} 4$,

$\mathrm{M}_{\text {sea, }}$, the total annual mass of macroplastics that may reach the sea, i.e. the macroplastic emission according to $\mathrm{H} 4$ and $\mathrm{H} 5$,

$\mathrm{X}$, the fraction of tagged litter recovered relative to tagged litter released, which is the rate of collection by Naturaul'un according to $\mathrm{H} 2$.

We obtain the following equations,

$$
\begin{gathered}
M_{\text {naturauliun }}\left(1+a_{\text {min }}\right) \leq M_{\text {stranded }} \leq M_{\text {naturauliun }}\left(1+a_{\text {max }}\right) \\
M_{\text {estuary }}=\frac{M_{\text {stranded }}}{X} \quad \text { Eq.1 } \\
M_{\text {sea }}=M_{\text {estuary }}-M_{\text {naturauliun }}-M_{\text {mde }} \quad \text { Eq. } 3
\end{gathered}
$$

\section{Results}

\subsection{Quantity of riverine litter collected}


Since 2008, nearly 150 metric tons (mt) of plastic debris, 42,000 glass bottles, 17,500 aerosol cans and 10,000 syringes were collected among other riverine litter by Naturaul'un in the Seine estuary. There is no clear trend either increase or decrease of the quantities collected over time, but there are significant Pearson correlations with water flow (Figure 2; $\rho$ values of $0.55,0.52,0.38,0.63$ and 0.49 for respectively aerosols, glass bottles, syringes, plastic containers and plastic mass relative to water flow with p-value $<<0.01$ ). Before 2018, macroplastics were not weighed but the volume collected was reported and converted to masses. Since 2018, macroplastics are weighed separately by Naturaul'un. During this year, they removed around $20 \mathrm{mt}$ of riverine litter from the riverbanks, including $16 \mathrm{mt}$ of macroplastics.

\subsection{Rate of collection}

During the tagged-litter experiment (2018-2019), 36\% of the 365 items released were reported stranded between downstream Rouen and the outlet of the estuary either by Naturaul'un, citizen sciences or field campaigns. Among them, $43 \%$ were reported at least 2 times and 16\% were reported at least 3 times. One item was reported up to 7 times on 2 different sites. Some items were covered with biofilms and 6 items were fragmented, possibly by boat propellers. The latter mainly consisted in PP planters (Supp. Data 1, Table S2). Only one item was reported out of the estuary. It reached the sea and beached 145 days after its release $20 \mathrm{~km}$ North from Le Havre. It was an open milk bottle released during the winter-spring flood 2018 and recovered by a local NGO. Among the tagged items recovered were found plastics that usually sink like tires, PVC-pipes, PET-bottles (open), but also other material like glass bottles. In addition, $10 \%$ of the glass bottles and $25 \%$ of the aerosol cans were recovered, suggesting they are also easily transportable by the river. We thus combined those results with the plastic items for further discussion.

The tagged litter experiment was conducted for 1 year and 3 weeks, which enables to estimate a mean annual recovery rate of $28 \%(23.5 \%, 35.3 \%, 41.6 \%$ and $22.5 \%$ for items released in March, July, August and September, respectively; Figure 3). Naturaul'un made most of the recoveries because they were on the field 5/7 days a week, which makes the monitoring very efficient. On average, items were found stranded by Naturaul'un $88 \pm 90$ days after their release (median value of 62 days) and the median up/downstream distance travelled was $35 \mathrm{~km}$. The recovery rate for items released during the winter-spring flood in March 2018 (blue curve) reaches a plateau faster than the recovery rate of the other items. But, the recovery 
curves corresponding to the releases in low flow period do not reach a plateau, suggesting more tagged items would have been discovered if cleaning was not interrupted. To sum up, $80 \%$ of the collected items released in March were collected after 12 weeks. This proportion was reached after 27 weeks for items released in July, 23 weeks for those released in August and 22 weeks for those released in September. Notice a second round of recovery occurred for the tagged litter released during the winter/spring flood 2018 (blue curve) after the water height increased again during winter/spring 2019 (Figure 3).

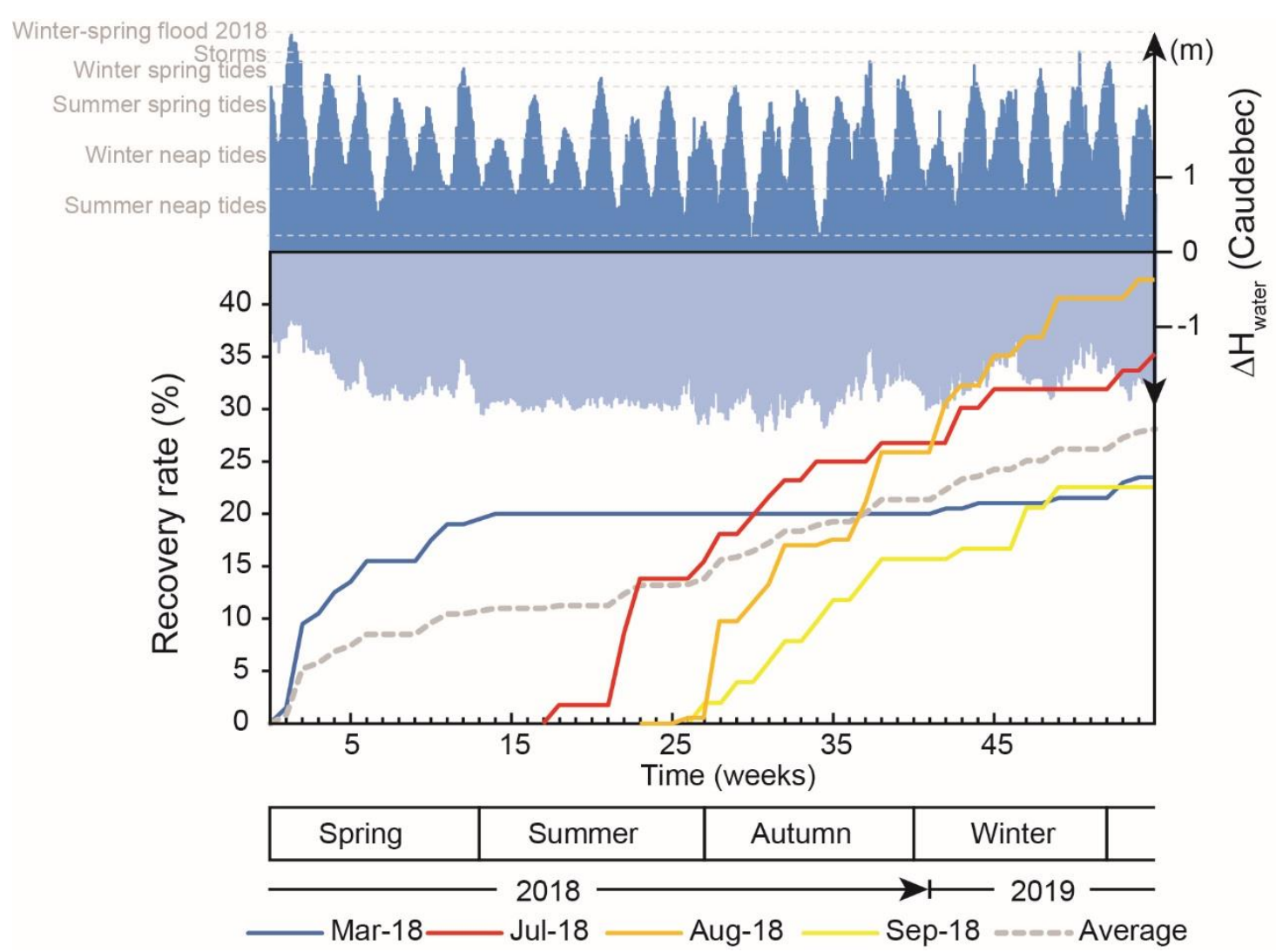

Figure 3: Evolution of the recovery rate of tagged litter by Naturaul'un relative to time and water height in Caudebec (cf. Figure 1A). The dashed grey line corresponds to the average recovery rate. The experimental lasted for 1 year and 3 weeks until the last interruption of cleaning. Reporting was performed weekly, that is why the time refers to the number of weeks passed after the first release of items.

\subsection{Macroplastic emission}

Using $M_{\text {naturaulıu. }}\left(1+a_{\text {min }}\right) \leq M_{\text {stranded }} \leq M_{\text {naturaulın }} \cdot\left(1+a_{\text {max }}\right) \quad$ Eq. 1 , the annual mass of macroplastic stranded $\mathrm{M}_{\text {stranded }}$, corresponding to the mass collected by Naturaul'un $\mathrm{M}_{\text {naturaul'un }}$ with the estimated mass left behind $\left(\mathrm{a}_{\min }=1.5\right.$ and $\left.\mathrm{a}_{\max }=3.4\right)$, is 
between 40 and $70 \mathrm{mt} / \mathrm{yr}$. According to the recovery rate by Naturaul'un, those quantities correspond to $28 \%$ of the macroplastic mass annually circulating in the estuary $\mathrm{M}_{\text {estuary }}$, which is given by the $M_{\text {estuary }}=\frac{M_{\text {stranded }}}{X} \quad$ Eq. 2, i.e. $142-250 \mathrm{mt} / \mathrm{yr}$. This is about 9-15 g/cap/yr. Considering the amount of macroplastics annually removed from the estuary by Naturaul'un and La Maison de l'estuaire, i.e. $26 \mathrm{mt} / \mathrm{yr}$, the maximum annual macroplastic emission $M_{\text {sea }}$ is $116-224 \mathrm{mt} / \mathrm{yr}\left(M_{\text {sea }}=M_{\text {estuary }}-M_{\text {naturauliun }}-M_{\text {mde }} \quad\right.$ Eq. 3$)$. The figure of $100-200 \mathrm{mt} / \mathrm{yr}$ is retained for the discussion, which is about 6-12 g/cap/yr in the catchment. Then, institutional cleaning in the Seine estuary contribute to reduce macroplastic emissions of about $10 \%$ to $20 \%$.

\section{Discussion}

\section{Method sensitivity and representativeness}

Field methods (e.g. visual counting, passive/active sampling or a combination of these) are usually facing strong spatial and temporal variability related to seasonality and sampling methods (van der Wal et al., 2015; Crosti et al., 2018; Castro-Jiménez et al., 2019; van Emmerik et al., 2019a, 2019b). In contrast, our methodology is based on a huge dataset built from daily cleaning of the estuarian riverbanks, hence covering large spatiotemporal scales and a wide range of marine and hydrometeorological conditions, including low water periods, storms, highest tides or flood events, low and high atmospheric pressure. The great representativeness of the riverbanks regarding the level of riverine litter is supported by the significant correlation between the quantities of litter collected and water flow (Figure 2). Also, the tagged litter were always found among other debris and often entangled in organic debris.

Flood events are expected to introduce huge amount of riverine litter in the estuary together with organic debris (van Emmerik et al., 2019a), but to date no data were available to estimate their contribution to the global plastic input. The winter/spring flood 2018 brought huge amount of riverine litter in the estuary as suggested by the peak of collection during and right after this event (Figure 2). The steep recovery rate (blue curve, Figure 3) suggests that recoverable debris, i.e. debris deposited at the top of riverbanks, were recovered quickly. The significant recovery rate $(\sim 20 \%)$ also suggests that a similar fraction of the riverine litter was removed, whereas the remaining fraction may have reached the sea, favored by high river discharge. However, it may also have been stored on unexplored riverbanks and partially remobilized as suggested by a second round of recovery after subsequent water level increase during the next winter (Figure 3). Thus, flood events may both enhance the output of riverine 
litter into the sea and increase the residence time of the remaining litter, settled very high on riverbanks or in flood plains. This is in agreement with (i) the GPS-tracking of plastic litter, which showed a significant greater up to downstream distance travelled during flood than during regular hydrological conditions (Tramoy et al., 2020b), and (ii) the huge amount of old litter settled in floodable areas nearby the main channel or higher up on unexplored riverbanks (Tramoy et al., 2020a). Those empirical observations support a recent model that coupled flood extends and high resolution mismanaged plastic waste data in rivers (Roebroek et al., 2020). They suggested that 10 -year return period floods could tenfold the global plastic mobilization potential compared to non-flood conditions.

The great diversity of items found on riverbanks, which include plastics that sink like plastic foils and films, PET-bottles, PVC-pipes, glass bottles etc., and their ability to strand with tides and wind suggest the riverbanks integrate most of the debris flowing into the estuary, either at the water surface or in the water column independently of their buoyancy. This is in agreement with Bernardini et al. (2020) who compared items found on the foreshore of the Thames river according to two deposition processes occurring on sites: "sinking sites" where plastic tends to sink into the sediment and "floating sites" where plastic accumulated on the upper part of the sediment. They found much higher abundance and richness of items in "floating sites" than in "sinking sites". Similar results were obtained in three German rivers where the largest diversity of items was found on riverbanks when compared to water surface, water column, beaches and riverbed (Schöneich-Argent et al., 2020). Those authors also reported it was not clear whether debris are preferentially carried by water surface or the water body, highlighting the need to assess simultaneously the water column and its surface or to focus on riverbanks which can integrate both. Although the occurrence of debris either at the water surface or in the water column is related to their buoyancy (Ryan, 2015), their vertical distribution is a function of the water turbulence as demonstrated at sea (Reisser et al., 2015). Thus, plastic debris may switch from the water surface to the water column and vice versa with hydrological changes, which makes difficult the monitoring of plastic debris over a long period. For those reasons, we claim that deposits on riverbanks are a consequence of all the dynamic processes that occur in the water body and, that all the debris found on riverbanks are good indicators of the level of riverine litter flowing in water. However, other authors suggested that recreational activities were the main contributor of plastic pollution on riverbanks rather than illegal dumping or river deposits in German rivers (Kiessling et al., 2019). So, the location, duration and frequency of cleaning should be carefully considered to decipher a river signal 
and riverine OSPAR protocols combined with institutional cleaning should be extensively implemented (Vriend et al., 2020a).

In estuaries, tides represent additional difficulties to accurately quantify macroplastic emissions because they greatly impact the dynamics of debris with back and forth water movements, and the potential remobilization of sinks (van Emmerik et al., 2019a, 2019b; Vriend et al., 2020b; Tramoy et al., 2020a). This aspect is usually hard to address with methods like visual counting unless they are performed intensively over time and space, while recent models only refer to obstacles on the water course with dams and do not consider other temporary sinks like meanders or flood plains (Lebreton et al., 2017). Again, regular cleanings smooth the resulting variability because (i) they explore large areas, i.e. $20 \mathrm{~km}$ of riverbanks at the downstream part of the Seine river, which is $13 \%$ of the natural riverbanks (GIP SeineAval, 2011), (ii) they collect thousands of debris and (iii) they remove debris from the water system, i.e. they cannot be counted twice. They also increase the probability to collect debris relative to passive sampling in water because debris are most of the time stranded on riverbanks rather flowing in water (Tramoy et al., 2020b). Then, our estimate of $\sim 100-200 \mathrm{mt} / \mathrm{yr}$ of macroplastic emissions is very reliable, even though it should be considered as a maximum because of Hypothesis 2 and 5. In fact, non-recovered tagged litter, related to Hypothesis 2 in our calculations, may be stored in the highest riverbanks and/or trapped in vegetation for a long time on sites that are not cleaned, as suggested by personal observations and date-print items (Tramoy et al., 2020a). Alternatively, it could have been removed by other people who were not aware of our experiment, despite an intensive local communication, which happened one time to our knowledge (the item has consequently been removed from the data). The same reasons may affect Hypothesis 5.

\section{Comparison with models and other field approaches}

Previous estimates of the macroplastic load in the Seine River greatly differ from the present one (Table 1). On one hand, estimates based on floating booms in Paris megacity yield $1,100-1,700 \mathrm{mt} / \mathrm{yr}$ and estimations based on Jambeck' approach yield 2,200-5,900 mt/yr (Tramoy et al., 2019), which is one order of magnitude higher than our present estimates. On the other hand, visual counting were performed during low and high water periods in the Seine River and showed that plastic debris tenfolded between the two periods from $\sim 100 \mathrm{part} / \mathrm{h}$ to $\sim 1,000 \mathrm{part} / \mathrm{h}$ in the upstream part of the estuary (van Emmerik et al., 2019b). Using the mass distribution of thousands of macroplastics found in 3 German rivers, i.e median value of $1.7 \mathrm{~g}$ 
and $10.6 \mathrm{~g}$ in average (Schöneich-Argent et al., 2020), the minimized-maximized macroplastic emission in the Seine River would be $1-15 \mathrm{mt} / \mathrm{yr}$ and $9-93 \mathrm{mt} / \mathrm{yr}$. This is up to one to two orders of magnitude lower than our estimates, i.e. 100-200 mt/yr, but closer to Lerebton's (9$45 \mathrm{mt} / \mathrm{yr}$ ) and Schmidt's (9-20 mt/yr) estimates based on Jambeck' approach and calibrated with microplastics field data (Lebreton et al., 2017; Schmidt et al., 2017).

Table 1: Macroplastic emission estimates in the Seine River.

\begin{tabular}{|c|c|c|c|c|}
\hline \multirow{2}{*}{ Reference } & Method used & $\begin{array}{c}|c| \\
\text { Plastic emission }\end{array}$ & \multirow{2}{*}{ Comment } \\
\cline { 2 - 4 } & scale (mt/yr) & $\begin{array}{c}\text { Per capita } \\
\text { (g/cap) }\end{array}$ & \\
\hline $\begin{array}{c}\text { Schirinzi et al. } \\
2020\end{array}$ & Visual counting & $0.4-0.6$ & $0.09-0.1$ & Mass conversion issues? \\
\hline Tramoy et al. 2019 & Jambeck'approach & $2,200-5,900$ & $132-353$ & Uncalibrated model \\
\hline Tramoy et al. 2019 & Floating booms & $1,100-1,700$ & $66-102$ & Rough extrapolations \\
\hline $\begin{array}{c}\text { Our study } \\
\text { combined with tagged litter }\end{array}$ & $100-200$ & $6-12$ & $\begin{array}{c}\text { Very integrative with } \\
\text { high spatiotemporal } \\
\text { resolution }\end{array}$ \\
\hline $\begin{array}{c}\text { Van Emmerik et al. } \\
\text { 2019 }\end{array}$ & Visual counting & $1-93 *$ & $0.06-6$ & $\begin{array}{c}\text { Low spatiotemporal } \\
\text { resolution }\end{array}$ \\
\hline Lebreton_et al. \\
(2017)
\end{tabular}

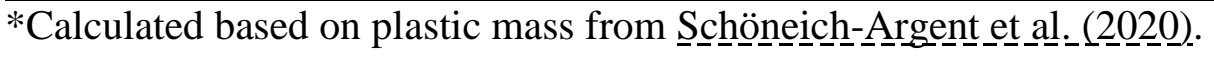

In other Europeans rivers, field estimates based on visual counting and passive sampling or other holistic approach resulted in underestimations when compared to models. This was the case for the Rhône (Castro-Jiménez et al., 2019), the Rhine (Vriend et al., 2020b), the Ems, the Elbe or the Weser in Germany (Schöneich-Argent et al., 2020). In contrast, visual counting in two Catalan rivers gave similar results to models, probably because of number to mass conversion issues that were based on polymer type of items and not an empirical mass value per item (Schirinzi et al., 2020). Those discrepancies between and within model- and fieldbased methods are explained by (i) differences in baseline data from which the estimates are calculated, (ii) the uncertainty in item/mass ratio, (iii) a biased relation between catchment runoff and plastic transport, which is an artifact of the calibration data, or (iv) the large uncertainties related to transfer dynamics of plastics (Schöneich-Argent et al., 2020; Vriend et 
al., 2020b). For example, model-based studies were mainly calibrated with field measurements related to microplastics and abundances to mass conversion were based on trawl net techniques resulting in underestimation of the mean mass of riverine macroplastics: $0.2 \mathrm{~g} /$ particle in average for Schmidt et al. (2017) and 0.04 to $0.3 \mathrm{~g}$ for Lebreton et al. (2017), when compared to other collection techniques that gives $3.2 \mathrm{~g} /$ particle on average for van Emmerik et al. (2018) in the Saigon River (huge nets), $10.6 \mathrm{~g} /$ particle for Schöneich-Argent et al. (2020) in German rivers (hand collection, huge nets), and $5.4 \mathrm{~g} / \mathrm{particle}$ for Vriend et al. (2020) in the Rhine (passive sampling with litter trap). It therefore highlights the collection technique as a main driver of the macroplastic load estimates, trawl nets being not suitable for macroplastics because they are too small and not exposed long enough (Lechner et al., 2014; van der Wal et al., 2015). In our study, cleaning by Nautraul'un in the Seine estuary avoids the use of such mass conversions and shows relatively high number of large macroplastics $(>50 \mathrm{~cm})$ like jugs, planters, pipes, etc. that are usually not reported in studies dealing with plastic emission estimates.

If only the largest fraction of macroplastics is considered in the Seine estuary (the one harvestable by Naturaul'un, i.e. $>5 \mathrm{~cm}$, hence ruling out $\mathrm{a}_{\min }$ and $\mathrm{a}_{\max }$ in equation 1), then the annual macroplastic emission is around $30 \mathrm{mt} / \mathrm{yr}$. This is almost equivalent to the quantity which is removed by Naturaul'un (16 mt/yr) and the NGO "Maison de l'estuaire" (10 mt/yr). So, almost $50 \%$ of the largest fraction of macroplastics is removed each year from the estuary. If smaller/hidden macroplastics (> $5 \mathrm{~mm}$ ) are included, i.e. annual macroplastic emission of 100-200 $\mathrm{mt} / \mathrm{yr}$, the fraction removed by institutional cleanings would be only 10\% to 20\% of the total macroplastics in the estuary. Mostly because $60 \%$ to $75 \%$ of those macroplastics are not collected (i.e. $a_{\min }$ and $a_{\max }$ ).

When compared to the MPW generated in the catchment calculated by Schmidt et al. (2017), the annual emission of the largest macroplastic corresponds to about $0.13 \%$ (30 mt/yr) of the MPW. It becomes $0.45-0.91 \%(100-200 \mathrm{mt} / \mathrm{yr})$ of the MPW when considering the smaller/hidden macroplastics. The fraction of MPW emitted to the sea was similar in German rivers (0.001\%-0.76\%; Schöneich-Argent et al., 2020), but higher in Jarkarta (3\%; Van Emmerik et al. 2019). The Seine estuary is then in the upper range of rivers in Europe, which is in agreement with comparative visual counting across few world rivers also showing Asian rivers as the most polluted rivers (van Calcar and van Emmerik, 2019). Nevertheless, the fraction of MPW entering the sea remains extremely low. This may indicate that management strategies in "developed" countries are efficient with most of MPW collected before they enter 
the hydrosystem and the estuary. A second option would be that it is the result of an overestimation of the MPW generated in the catchment, because calculations are related to key parameters poorly improved (e.g. the $2 \%$ of leakage; Tramoy et al., 2019). This option is also supported by the discrepancy between field and model estimates of the annual flux of plastics from Cape Town, South Africa. There, the annual flux of plastics was overestimated by one order of magnitude with the Jambeck'model relative to ground-truth data based on urban stormwater run-off and litter accumulated on beaches (Weideman et al., 2020a). A third option would be that MPW remain in soils, flood plains, coast lines and urban areas, which act as potential sinks for plastic debris as suggested by recent studies (Brennan et al., 2018; Olivelli et al., 2020; Tramoy et al., 2021; Weideman et al., 2020b). This is supported by the distance travelled by macroplastics from their source emission. In this study, the median up/downstream distance travelled by the recovered tagged litter is only $35 \mathrm{~km}$. It was $19 \mathrm{~km}$ in the estuary for the GPS-bottles over shorter periods, with stepwise transport related to storage/remobilization episodes (Tramoy et al., 2020b). The same pattern was obtained in the Ganges River using similar technologies with a median up/downstream distance travelled of $32 \mathrm{~km}$ (Duncan et al., 2020). Limited long-distance travelled by macroplastics from their source emission was also reported by (Weideman et al., 2020b) in Orange-Vaal River system, South Africa. Thus, cleaning of riverbanks might be the most efficient curative solution. Anyway, the fate of collected macroplastics removed from hydrosystems is often incineration rather than recycling because of their bad quality, whereas the remaining fraction may reach the sea or accumulate in the estuary until they get fragmented, removed, buried or a combination of these.

\section{Recommendations and concluding remarks}

The framework of this study is based on institutional cleaning in the Seine estuary performed by Naturaul'un. The aim of local authorities is to clean riverbanks, as much as possible, for touristic, ecological and economic interests. We thus encourage researchers to work together with those cleaning programs to gather "ground-truth" data and better estimate the level of plastic pollution in rivers. The tagged litter experiment presented in this study is a reliable way to evaluate the impact of cleaning in reducing the amount of riverine litter entering the sea. But it should be improved using for example a classification of the items released according to their buoyancy (e.g. negative, positive, neutral) to check if riverbanks integrate all type of items, in the same proportion before their release and after their collection. Further improvement could be achieved if the tagged litter approach was combined with standardized Riverine-OSPAR protocols which are under consideration today (van Emmerik et al., 2020). 
Overall, cleaning of riverbanks is cost-effective, low-tech and armless for flora and fauna compared to floating booms in Paris (Gasperi et al., 2014 and personal communication about the respective costs), and provides low-qualified jobs meeting economic, social and ecological goals. In the opposite, technological "end of pipe" solutions aiming to remove plastics from the oceans would reach indecent costs (Cordier and Uehara, 2019). To our opinion, cleaning the riverbanks are the best curative solution if curative solution in rivers are undertaken, before macroplastics get fragmented into microplastics.

In addition, the deep analysis of the cumulated mass of macroplastic debris collected since 2008 relative to the water flow shows that almost $60 \%$ of the mass was collected during low water flow, i.e. below the average of $500 \mathrm{~m}^{3} / \mathrm{s}$ recorded in Vernon (Figure 4). Quantities of debris collected are usually lower during low water flow, but those periods represent longer time. Even though high river discharge may recharge the estuary in riverine litter and enhance their transfer to the sea (Krelling and Turra, 2019; Tramoy et al., 2020b), the cleanable fraction may be cleaned over a long period following the high river discharge period. This may be related to a funneling effect with the arrival of huge amount of debris while the capacity of collection remains unchanged over time and space. However, $40 \%$ of the debris are collected during high flow periods. Such periods result in greater abundance and diversity in items deposited on riverbanks and beaches in estuaries (Krelling and Turra, 2019; Schöneich-Argent et al., 2020). Hence, to enhance its efficiency, cleaning must be reinforced during and right after flood events, and a constant effort should be maintained the rest of the year, during low river discharge periods. However, authorities should keep in mind that curative solutions are dealing with a very small fraction of the MPW (Schneider et al., 2018).

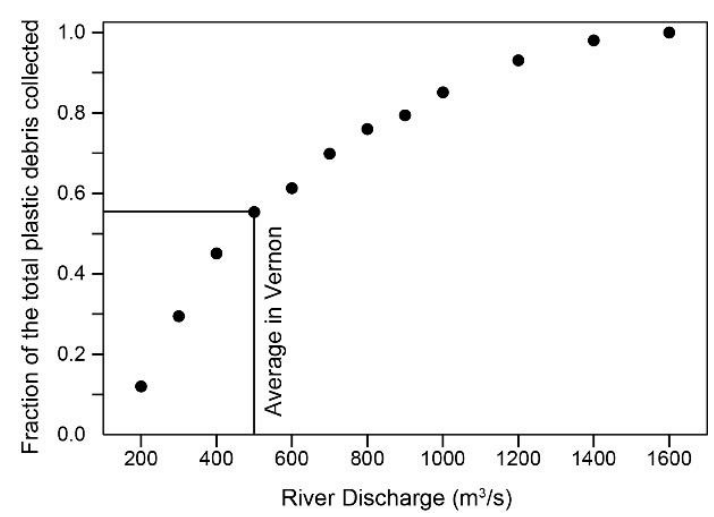

Figure 4: Fraction of the total mass of macroplastic debris monthly collected since 2008 relative to monthly water flow ranged by classes $\left(<200 \mathrm{~m}^{3} / \mathrm{s},<300 \mathrm{~m}^{3} / \mathrm{s}\right.$, etc.). The vertical line corresponds to the average water flow in Vernon, upstream the Seine estuary. 
Based on the plastic mass collected by Naturaul'un, the tagged litter experiment and what we have learned about the transfer dynamics of plastic debris in the estuary (see Part 1 and Part 2 of this paper trilogy), the annual macroplastic emission from the Seine estuary to the sea was estimated to $\sim 100-200 \mathrm{mt} / \mathrm{yr}$. It decreases to $30 \mathrm{mt} / \mathrm{yr}$ if the largest macroplastic debris only are considered. The spatiotemporal resolution of the developed methodology is incomparably higher than other methods commonly used like visual counting. It consequently yields robust estimates, compared to estimates usually reported in literature. It also yields maximum estimates considering our experimental design in opposite to most of studies that propose conservative estimates. The relatively high efficiency of cleaning operations is perhaps related to the specific configuration of the Seine estuary with huge meanders, large natural riverbanks with gentle slopes, a macro-tidal regime and well-mixed water (Meybeck et al., 1998; Grasso et al., 2018). According to Acha et al. (2003), the Río de la Plata salt wedge estuary acts as a physical barrier to the transfer of riverine litter to the sea with much more waste accumulated close to the bottom salinity on both estuary floor and shorelines. Our findings show that wellmixed estuaries like the Seine estuary may act similarly. Then, other estuaries and other type of land-ocean interface like deltas should be investigated to improve the reproducibility of our methodology that uses institutional cleaning.

Although this curative solution only collects a small fraction of all the MPW generated in the catchment, it is relatively efficient and of utmost importance, because institutional cleaning (Naturaul'un and the NGO "Maison de l'estuaire) remove from the estuary each year $~ 50 \%$ of the largest/visible macroplastics and $\sim 10 \%$ to $\sim 20 \%$ of the total macroplastics. However, the large amount of smaller/hidden litter left behind $-60 \%$ to $75 \%$ of the macroplastics are not collected during the cleaning operations - also shows that curative solutions themselves will never be enough to achieve the national goal of zero plastic emission and $100 \%$ plastic waste recycled by 2025 (https://www.ecologique-solidaire.gouv.fr/sites/default/files/18xxx_Planbiodiversite-04072018_28pages_FromPdf_date_web_PaP.pdf).

Cleaning efficiency could be improved with a better cleaning strategy (e.g. more cleaning teams and people, more sites investigated, a more thorough cleaning), but because of the law of diminishing returns, the marginal cost of the cleaning will become inaccessible to the community. To date, the best litter removal-cost ratio remains unknown and demand furtherat least empirical - investigations. Anyway, it could be the baseline for an efficient monitoring 
of riverine litter over wide space and time scales, which is needed to evaluate mitigation strategies like single-use plastic bans.

Finally, our results suggest that model-based estimates (Lebreton et al., 2017; Schmidt et al., 2017) and visual counting (van Emmerik et al., 2019b) underestimate the plastic load in the Seine estuary and probably in other rivers for different reasons. The model-based estimates exhibit calibration issues and demand further improvement, whereas visual counting methods often miss extreme events as well as the water column compartment resulting in a low spatiotemporal representativeness. But, in contrast to our methodology, visual counting combined (or not) with passive sampling are easy to implement in any rivers with minimal efforts and can significantly improve field datasets for models. It makes visual counting suitable for rapid assessment of macroplastic emissions, especially in most polluted rivers, whereas our methodology would be more suitable in a second step, especially in the least polluted rivers.

\section{Acknowledgement}

We warmly thank all institutions who collaborated with us, especially GPMR, GIPSA (C. Fisson) and CD76 (B. Viault). Special thanks to Naturaul'un and M. Calleau for the tagged litter reporting. This research is funded by the French Ministry of the Ecological and Solidarity Transition.

\section{References}

Acha, E.M., Mianzan, H.W., Iribarne, O., Gagliardini, D.A., Lasta, C., Daleo, P., 2003. The role of the Río de la Plata bottom salinity front in accumulating debris. Mar. Pollut. Bull. 46, 197-202. https://doi.org/10.1016/S0025-326X(02)00356-9

Bernardini, G., McConville, A., Castillo Castillo, A., 2020. Macro-plastic pollution in the tidal Thames: An analysis of composition and trends for the optimization of data collection. Mar. Policy 119, 104064. https://doi.org/10.1016/j.marpol.2020.104064

Brennan, E., Wilcox, C., Hardesty, B.D., 2018. Connecting flux, deposition and resuspension in coastal debris surveys. Sci. Total Environ. 644, 1019-1026. https://doi.org/10.1016/j.scitotenv.2018.06.352

Browne, M.A., Galloway, T.S., Thompson, R.C., 2010. Spatial Patterns of Plastic Debris along Estuarine Shorelines. Environ. Sci. Technol. 44, 3404-3409. https://doi.org/10.1021/es903784e

Bruge, A., Barreau, C., Carlot, J., Collin, H., Moreno, C., Maison, P., Bruge, A., Barreau, C., Carlot, J., Collin, H., Moreno, C., Maison, P., 2018. Monitoring Litter Inputs from the Adour River (Southwest France) to the Marine Environment. J. Mar. Sci. Eng. 6, 24. https://doi.org/10.3390/jmse6010024

Castro-Jiménez, J., González-Fernández, D., Fornier, M., Schmidt, N., Sempéré, R., 2019. Macro-litter in surface waters from the Rhone River: Plastic pollution and loading to the NW 
Mediterranean Sea. Mar. Pollut. Bull. 146, 60-66.

https://doi.org/10.1016/j.marpolbul.2019.05.067

Cheung, P.K., Cheung, L.T.O., Fok, L., 2016. Seasonal variation in the abundance of marine plastic debris in the estuary of a subtropical macro-scale drainage basin in South China. Sci. Total Environ. 562, 658-665. https://doi.org/10.1016/j.scitotenv.2016.04.048

Cordier, M., Uehara, T., 2019. How much innovation is needed to protect the ocean from plastic contamination? Sci. Total Environ. 670, 789-799. https://doi.org/10.1016/j.scitotenv.2019.03.258

Crosti, R., Arcangeli, A., Campana, I., Paraboschi, M., González-Fernández, D., 2018. 'Down to the river': amount, composition, and economic sector of litter entering the marine compartment, through the Tiber river in the Western Mediterranean Sea. Rendiconti Lincei Sci. Fis. E Nat. 29, 859-866 https://doi.org/10.1007/s12210-018-0747-y

Duncan, E.M., Davies, A., Brooks, A., Chowdhury, G.W., Godley, B.J., Jambeck, J., Maddalene, T., Napper, I., Nelms, S.E., Rackstraw, C., Koldewey, H., 2020. Message in a bottle: Open source technology to track the movement of plastic pollution. PLOS ONE 15, e0242459. https://doi.org/10.1371/journal.pone.0242459

Emmerik, T. van, Loozen, M., Oeveren, K. van, Buschman, F., Prinsen, G., 2019. Riverine plastic emission from Jakarta into the ocean. Environ. Res. Lett. 14, 084033. https://doi.org/10.1088/1748-9326/ab30e8

Gasperi, J., Dris, R., Bonin, T., Rocher, V., Tassin, B., 2014. Assessment of floating plastic debris in surface water along the Seine River. Environ. Pollut. 195, 163-166. https://doi.org/10.1016/j.envpol.2014.09.001

Geraeds, M., van Emmerik, T., de Vries, R., bin Ab Razak, M.S., 2019. Riverine Plastic Litter Monitoring Using Unmanned Aerial Vehicles (UAVs). Remote Sens. 11, 2045. https://doi.org/10.3390/rs11172045

GIP Seine-Aval, 2011. Cartographie des zones riveraines de l'estuaire de la Seine. Nature, état et accessibilité des berges. (Atlas). GIP Seine-Aval, Rouen.

González-Fernández, D., Hanke, G., 2017. Toward a Harmonized Approach for Monitoring of Riverine Floating Macro Litter Inputs to the Marine Environment. Front. Mar. Sci. 4. https://doi.org/10.3389/fmars.2017.00086

Grasso, F., Verney, R., Hir, P.L., Thouvenin, B., Schulz, E., Kervella, Y., Fard, I.K.P., Lemoine, J.-P., Dumas, F., Garnier, V., 2018. Suspended Sediment Dynamics in the Macrotidal Seine Estuary (France): 1. Numerical Modeling of Turbidity Maximum Dynamics. J. Geophys. Res. Oceans 123, 558-577. https://doi.org/10.1002/2017JC013185

Ivar do Sul, J.A., Costa, M.F., Silva-Cavalcanti, J.S., Araújo, M.C.B., 2014. Plastic debris retention and exportation by a mangrove forest patch. Mar. Pollut. Bull. 78, 252-257. https://doi.org/10.1016/j.marpolbul.2013.11.011

Jambeck, J.R., Geyer, R., Wilcox, C., Siegler, T.R., Perryman, M., Andrady, A., Narayan, R., Law, K.L., 2015. Plastic waste inputs from land into the ocean. Science $347,768-771$. https://doi.org/10.1126/science.1260352

Krelling, A.P., Turra, A., 2019. Influence of oceanographic and meteorological events on the quantity and quality of marine debris along an estuarine gradient. Mar. Pollut. Bull. 139, 282-298. https://doi.org/10.1016/j.marpolbul.2018.12.049

Kurniawan, S.B., Imron, M.F., 2019a. Seasonal variation of plastic debris accumulation in the estuary of Wonorejo River, Surabaya, Indonesia. Environ. Technol. Innov. 16, 100490. https://doi.org/10.1016/j.eti.2019.100490

Kurniawan, S.B., Imron, M.F., 2019b. The effect of tidal fluctuation on the accumulation of plastic debris in the Wonorejo River Estuary, Surabaya, Indonesia. Environ. Technol. Innov. 15, 100420. https://doi.org/10.1016/j.eti.2019.100420 
Lebreton, L.C.M., van der Zwet, J., Damsteeg, J.-W., Slat, B., Andrady, A., Reisser, J., 2017. River plastic emissions to the world's oceans. Nat. Commun. 8, 15611. https://doi.org/10.1038/ncomms15611

Lechner, A., Keckeis, H., Lumesberger-Loisl, F., Zens, B., Krusch, R., Tritthart, M., Glas, M., Schludermann, E., 2014. The Danube so colourful: A potpourri of plastic litter outnumbers fish larvae in Europe's second largest river. Environ. Pollut. 188, 177-181. https://doi.org/10.1016/j.envpol.2014.02.006

Lerond, M., 1997. Définition des conditions de mise en oeuvre du nettoyage de la Seine - Synthèse. Parc Naturel Regional de Brotonne.

Mazarrasa, I., Puente, A., Núñez, P., García, A., Abascal, A.J., Juanes, J.A., 2019. Assessing the risk of marine litter accumulation in estuarine habitats. Mar. Pollut. Bull. 144, 117-128. https://doi.org/10.1016/j.marpolbul.2019.04.060

Meybeck, M., de Marsily, G., Fustec, E., 1998. La Seine et son bassin. Fonctionnement écologique d'un système fluvial anthropisé. Elsevier, Paris, France.

Olivelli, A., Hardesty, D., Wilcox, C., 2020. Coastal margins and backshores represent a major sink for marine debris: insights from a continental-scale analysis. Environ. Res. Lett. https://doi.org/10.1088/1748-9326/ab7836

Reisser, J., Slat, B., Noble, K., du Plessis, K., Epp, M., Proietti, M., de Sonneville, J., Becker, T., Pattiaratchi, C., 2015. The vertical distribution of buoyant plastics at sea: an observational study in the North Atlantic Gyre. Biogeosciences 12, 1249-1256. https://doi.org/10.5194/bg12-1249-2015

Roebroek, C., Harrigan, H., van Emmerik, T., Baugh, C., Eilander, D., Prudhomme, C., Pappenberger, F., 2020. Plastic in global rivers: are floods making it worse? https://doi.org/10.21203/rs.3.rs-43330/v1

Ryan, P.G., 2015. Does size and buoyancy affect the long-distance transport of floating debris? Environ. Res. Lett. 10, 084019. https://doi.org/10.1088/1748-9326/10/8/084019

SAFEGE, R., 2012. Etude sur la caractérisation et les flux de déchets en milieux aquatiques. SAFEGEADEME, Angers.

Schirinzi, G.F., Köck-Schulmeyer, M., Cabrera, M., González-Fernández, D., Hanke, G., Farré, M., Barceló, D., 2020. Riverine anthropogenic litter load to the Mediterranean Sea near the metropolitan area of Barcelona, Spain. Sci. Total Environ. 714, 136807. https://doi.org/10.1016/j.scitotenv.2020.136807

Schmidt, C., Krauth, T., Wagner, S., 2017. Export of Plastic Debris by Rivers into the Sea. Environ. Sci. Technol. https://doi.org/10.1021/acs.est.7b02368

Schneider, F., Parsons, S., Clift, S., Stolte, A., McManus, M.C., 2018. Collected marine litter - A growing waste challenge. Mar. Pollut. Bull. 128, 162-174. https://doi.org/10.1016/j.marpolbul.2018.01.011

Schöneich-Argent, R.I., Dau, K., Freund, H., 2020. Wasting the North Sea? - A field-based assessment of anthropogenic macrolitter loads and emission rates of three German tributaries. Environ. Pollut. 263, 114367. https://doi.org/10.1016/j.envpol.2020.114367

Tramoy, R., Colasse, L., Gasperi, J., Tassin, B., 2019. Plastic debris dataset on the Seine river banks: Plastic pellets, unidentified plastic fragments and plastic sticks are the Top 3 items in a historical accumulation of plastics. Data Brief 23, 103697. https://doi.org/10.1016/j.dib.2019.01.045

Tramoy, R., Gasperi, J., Colasse, L., Silvestre, M., Dubois, P., Noûs, C., Tassin, B., 2020b. Transfer dynamics of macroplastics in estuaries - New insights from the Seine estuary: Part 2. Shortterm dynamics based on GPS-trackers. Mar. Pollut. Bull. 160, 111566. https://doi.org/10.1016/j.marpolbul.2020.111566

Tramoy, R., Gasperi, J., Colasse, L., Tassin, B., 2021. Transfer dynamic of macroplastics in estuaries New insights from the Seine estuary: Part 3. What fate for macroplastics? Mar. Pollut. Bull. https://doi.org/sous presse 
Tramoy, R., Gasperi, J., Colasse, L., Tassin, B., 2020a. Transfer dynamic of macroplastics in estuaries - New insights from the Seine estuary: Part 1. Long term dynamic based on date-prints on stranded debris. Mar. Pollut. Bull. 152, 110894. https://doi.org/10.1016/j.marpolbul.2020.110894

Tramoy, R., Gasperi, J., Dris, R., Colasse, L., Fisson, C., Sananes, S., Rocher, V., Tassin, B., 2019. Assessment of the plastic inputs from the Seine basin to the sea using statistical and field approaches. Front. Mar. Sci. 6. https://doi.org/10.3389/fmars.2019.00151

van Calcar, C.J. van, van Emmerik, T.H.M. van, 2019. Abundance of plastic debris across European and Asian rivers. Environ. Res. Lett. 14, 124051. https://doi.org/10.1088/1748-9326/ab5468

van der Wal, M., van der Meulen, M., Tweehuijsen, G., Peterlin, M., Palatinus, A., Kovac Virsek, M., Coscia, L., Krzan, A., 2015. Final Report on Identification and Assessment of Riverine Input of (Marine) Litter. Eunomia Research \& Consulting Ltd.

van Emmerik, T., Kieu-Le, T.-C., Loozen, M., van Oeveren, K., Strady, E., Bui, X.-T., Egger, M., Gasperi, J., Lebreton, L., Nguyen, P.-D., Schwarz, A., Slat, B., Tassin, B., 2018. A Methodology to Characterize Riverine Macroplastic Emission Into the Ocean. Front. Mar. Sci. 5. https://doi.org/10.3389/fmars.2018.00372

van Emmerik, T., Schwarz, A., 2020. Plastic debris in rivers. WIREs Water 7, e1398. https://doi.org/10.1002/wat2.1398

van Emmerik, T., Strady, E., Kieu-Le, T.-C., Nguyen, L., Gratiot, N., 2019a. Seasonality of riverine macroplastic transport. Sci. Rep. 9, 1-9. https://doi.org/10.1038/s41598-019-50096-1

van Emmerik, T., Tramoy, R., van Calcar, C., Alligant, S., Treilles, R., Tassin, B., Gasperi, J., 2019b. Seine Plastic Debris Transport Tenfolded During Increased River Discharge. Front. Mar. Sci. 6, 642. https://doi.org/10.3389/fmars.2019.00642

van Emmerik, T. van, Vriend, P., Roebroek, J., 2020. An evaluation of the River-OSPAR method for quantifying macrolitter on Dutch riverbanks. Wageningen University. https://doi.org/10.18174/519776

Vriend, P., Roebroek, C.T.J., van Emmerik, T., 2020a. Same but Different: A Framework to Design and Compare Riverbank Plastic Monitoring Strategies. Front. Water 2. https://doi.org/10.3389/frwa.2020.563791

Vriend, P., van Calcar, C., Kooi, M., Landman, H., Pikaar, R., van Emmerik, T., 2020b. Rapid Assessment of Floating Macroplastic Transport in the Rhine. Front. Mar. Sci. 7. https://doi.org/10.3389/fmars.2020.00010

Weideman, E.A., Perold, V., Arnold, G., Ryan, P.G., 2020a. Quantifying changes in litter loads in urban stormwater run-off from Cape Town, South Africa, over the last two decades. Sci. Total Environ. 724, 138310. https://doi.org/10.1016/j.scitotenv.2020.138310

Weideman, E.A., Perold, V., Ryan, P.G., 2020b. Limited long-distance transport of plastic pollution by the Orange-Vaal River system, South Africa. Sci. Total Environ. 727, 138653. https://doi.org/10.1016/j.scitotenv.2020.138653

Yao, W., Di, D., Wang, Z., Liao, Z., Huang, H., Mei, K., Dahlgren, R.A., Zhang, M., Shang, X., 2019. Micro- and macroplastic accumulation in a newly formed Spartina alterniflora colonized estuarine saltmarsh in southeast China. Mar. Pollut. Bull. 149, 110636. https://doi.org/10.1016/j.marpolbul.2019.110636 